\title{
AVALIAÇÃO DA ORGANIZAÇÃO ÁRBOREA E A PERCEPÇÃO DOS USUÁRIOS DAS PRAÇAS DO MUNICÍPIO DE MOCAJUBA, ESTADO DO PARÁ, BRASIL
}

\author{
EVALUATION OF THE ARBOREAL ORGANIZATION AND PERCEPTION OF USERS' \\ SQUARES OF MOCAJUBA MUNICIPALITY, STATE OF PARÁ, BRAZIL
}

Vanessa dos Santos Barros ${ }^{1}$, Cyntia Meireles Martins², Marcos Antônio Souza dos Santos ${ }^{3}$, Fabrício Khoury Rebello ${ }^{4}$, Charles Wendell Borges Monteiro ${ }^{5}$, Igor Sandro Borges Mesquita ${ }^{6}$

\section{RESUMO}

O uso de espécies exóticas arbóreas em detrimento das regionais nas vias urbanas dos municípios amazônicos ocorre pela falta de organização técnica e de planejamento, principalmente, devido à falta de conhecimento da legislação ambiental. O estudo analisa a arborização de cinco praças do município de Mocajuba, localizado no Nordeste Paraense, bem como a percepção dos seus usuários quanto aos seus serviços ambientais prestados e sua contribuição para a melhoria de bem-estar dos cidadãos. Para tanto, procedeu-se ao inventário florístico dos indivíduos arbóreos acerca do nome vulgar e nome científico, Circunferência à Altura do Peito (CAP) e, a altura estimada, além da aplicação de 100 questionários semiestruturados in loco em diferentes períodos, destinados aos frequentadores destes logradouros públicos, a fim de identificar sua percepção ambiental. Conforme identificado, atualmente são 37 árvores, de 10 famílias botânicas e 10 espécies arbóreas nesses logradouros públicos. A dominância de espécies exóticas ficou evidente, pois, apenas três espécies podem ser consideradas nativas, sendo as demais exóticas. Sobre a percepção dos usuários constatou-se que $83,3 \%$ possuem conhecimento sobre a importância da arborização nas praças estudadas, e na opinião de $73 \%$ dos pesquisados, as praças necessitam com urgência de melhor arborização, portanto, de ações públicas e de técnicas de planejamento e manutenção desses espaços.

Palavras-chave: Arborização; Meio ambiente; Municípios paraenses; Paisagismo; Planejamento urbano.

\section{ABSTRACT}

The use of exotic tree species in detriment of the regional ones in the urban streets of Amazonian municipalities occurs because of the lack of technical organization and planning, mainly due to the lack of knowledge of the environmental legislation. The research analyzes the afforestation of five squares of the municipality of Mocajuba, located in the Northeast of Pará, as well as the perception of its users regarding its environmental services rendered and its contribution to the improvement of the citizens' well-being. In order to do so, a floristic inventory of the arboreal individuals was performed on the common and scientific names, Circumference at Chest Height, and the estimated height, in addition to the application in loco of 100 semi-structured questionnaires in different periods in order to identify the users' environmental perception. As identified, there are currently 37 trees, 10 botanical families and 10 tree species in these public places. The dominance of exotic species was evident, since only three species can be considered native, the others being exotic. Regarding users' perception, $83.3 \%$ had knowledge about the importance of afforestation in the squares studied, and in the opinion of $73 \%$ of the surveyed, the squares urgently need better afforestation, therefore, public actions and planning and maintenance techniques of these spaces.

Keywords: Planting; Environment; Pará; Landscaping; Urban planning.

Recebido em 03.05.2018 e aceito em 16.01.2019

1 Engenheira Florestal. Universidade Federal Rural da Amazônia - UFRA. Belém/PA. Email: vanessabarros94@hotmail.com

2 Engenheira Agrônoma. Doutora. Professora da UFRA. Belém/PA. Email: cyntiamei@hotmail.com

3 Engenheiro Agrônomo. Doutor. Professor da UFRA. Belém/PA. Email: marcos.santos@ufra.edu.br

4 Economista. Doutor. Professor da UFRA. Belém/PA. Email: fabriciorebello@hotmail.com

5 Engenheiro Florestal. Universidade Federal Rural da Amazônia - UFRA. Belém/PA. Email: wendell_eng@hotmail.com

6 Estudante de Agronomia. Universidade Federal Rural da Amazônia - UFRA. Belém/PA. Email: igormesquita.agro@gmail.com 


\section{INTRODUÇÃO}

Cada vez mais os espaços públicos, em todo o mundo, devem desenvolver projetos de infraestrutura que assegurem logradouros mais harmônicos com a questão ambiental, a fim de garantir maior qualidade de vida à população (NIEMEYER, 2018). Bargos e Matias (2011) corroboram com a discussão acrescentando que essa importante função no espaço urbano, decorre de a vegetação em áreas urbanas propiciarem um ambiente mais agradável aos sentidos humanos, como o embelezamento paisagístico, o sombreamento, o conforto térmico, a qualidade do ar, entre outros atributos.

Na Amazônia, apesar da grande diversidade de espécies florestais com potencial para arborização, a maior parte das espécies inseridas no espaço urbano é de origem estrangeira. Entender a introdução de espécies exóticas nos centros urbanos brasileiros denota a compreensão dos processos de embelezamento da paisagem brasileira diante da influência das comunidades europeias já no período colonial do Brasil (DUARTE et al., 2018). Atualmente, o predomínio destas espécies induz estudos mais detalhados sobre a organização arbórea dos espaços públicos, condicionando, o planejamento urbano-florístico. Portanto, qualquer planejamento da arborização urbana não pode prescindir de um inventário criterioso, o qual permite contribuir para planos de ações de conservação e restauração florestal da biodiversidade nativa destes espaços (SILVA et al., 2007).

Vale destacar que o plantio de árvores, principalmente nos municípios de menor porte, ainda é feito de maneira aleatória, comumente ocasionando diversos problemas, tais como conflitos entre espécies de grande porte, perturbações na rede elétrica, danos na estrutura de calçadas devido ao avanço de raízes, entre outros. Tais problemáticas podem ser minimizadas a partir de um planejamento urbano mais eficaz, visando a organização e a ampliação das áreas verdes nos núcleos metropolitanos (LIMA NETO; SOUZA, 2011).

$\mathrm{Na}$ perspectiva de apresentar um panorama sobre a infraestrutura ambiental das cidades brasileiras, o Instituto Brasileiro de Geografia e Estatística (IBGE) realiza levantamento sobre Índices de Área Verde (IAV), que são expressos através da superfície de áreas verdes por habitante (IBGE, 2010). Segundo estudo do IBGE (2010), Goiânia (GO) ocupa a primeira posição no ranking da arborização das metrópoles brasileiras, com 89,5\% das ruas arborizadas, atualmente intitulada "Capital Verde do Brasil". Na sequência está Campinas (SP), com 88,4\%; Belo Horizonte (MG), com 83\%; Porto Alegre (RS), com 82,9\%; e Curitiba (PR), com 76,4\%. Na contramão destas estatísticas, Manaus (AM), com 25,1\% e; Belém (PA), com 22,3\% ficaram nas últimas posições, apesar destes estarem localizados na Amazônia, Bioma com a maior floresta tropical do mundo. 
O impacto causado pela presença de Belém entre as metrópoles com pior índice de arborização é um verdadeiro paradoxo, revelando uma preocupação sobre a manutenção e organização das vias urbanas em outros municípios paraenses. Loureiro e Barbosa (2010) destacam que Belém, capital do estado do Pará, demonstra inúmeras carências de áreas verdes, transformações ocorridas no seu espaço, principalmente, a partir da abertura de novas ruas, sistemas de tubulações e verticalização das construções, que contribuem para a diminuição da cobertura verde e, consequentemente, a perda da arborização urbana.

No Nordeste Paraense, uma das regiões de colonização mais antigas da Amazônia, encontra-se o município de Mocajuba, locus desse estudo, cujo valor de IAV é de apenas 19,7\% (IBGE, 2010). Apesar de possuir um forte atrativo ambiental e cultural, citando as recentes descobertas de espécies de mamíferos marinhos e, a forte presença religiosa, como o Festival de Nossa Senhora da Conceição, além da representatividade em atividades agrícolas tradicionais da economia paraense, a exemplo do plantio de pimenta-do-reino e dendê, percebese pelo baixo valor de IAV, a ausência de planejamento ambiental-urbano no município de Mocajuba que garanta um ambiente mais agradável à população local.

Assim, delineia-se o objetivo desse estudo no qual se busca quantificar a arborização nas praças e a percepção de seus usuários, tendo-se como unidade dessa análise o próprio município de Mocajuba (PA), o que pode contribuir com informações importantes para o planejamento ambiental-urbano, no tocante ao plano de arborização do município.

\section{MATERIAL E MÉTODOS}

\section{Área de estudo}

O Município de Mocajuba (Figura 1), distante da capital Belém cerca de 280 km, está situado na mesorregião do Nordeste Paraense e na microrregião de Cametá, sob coordenadas 02³5'03" S e 49³0'26" W, o qual possui aproximadamente $870,8 \mathrm{~km}^{2}$ de área. O principal rio que banha o município é o Tocantins onde se localizam as ilhas de Santana, Camaleão, Jutuba, Rufino e Angapijó. A população mocajubense está estimada em 30.377 habitantes e a densidade demográfica é de 30,70 habitantes por km² (IBGE, 2017). Conforme o Censo Demográfico de 2010, na região Norte, municípios com menos de 50 mil habitantes são considerados de pequeno porte, sendo este o caso do município de Mocajuba (IBGE, 2010).

O município tem sua origem em 1853, por lei provincial, tendo sido recriado pela Lei Estadual no 8, de 31/10/1935. A origem de sua designação, segundo a língua Nheengatú, quer dizer "lugar abundante de mucajás", que era uma palmeira farta na localidade. 


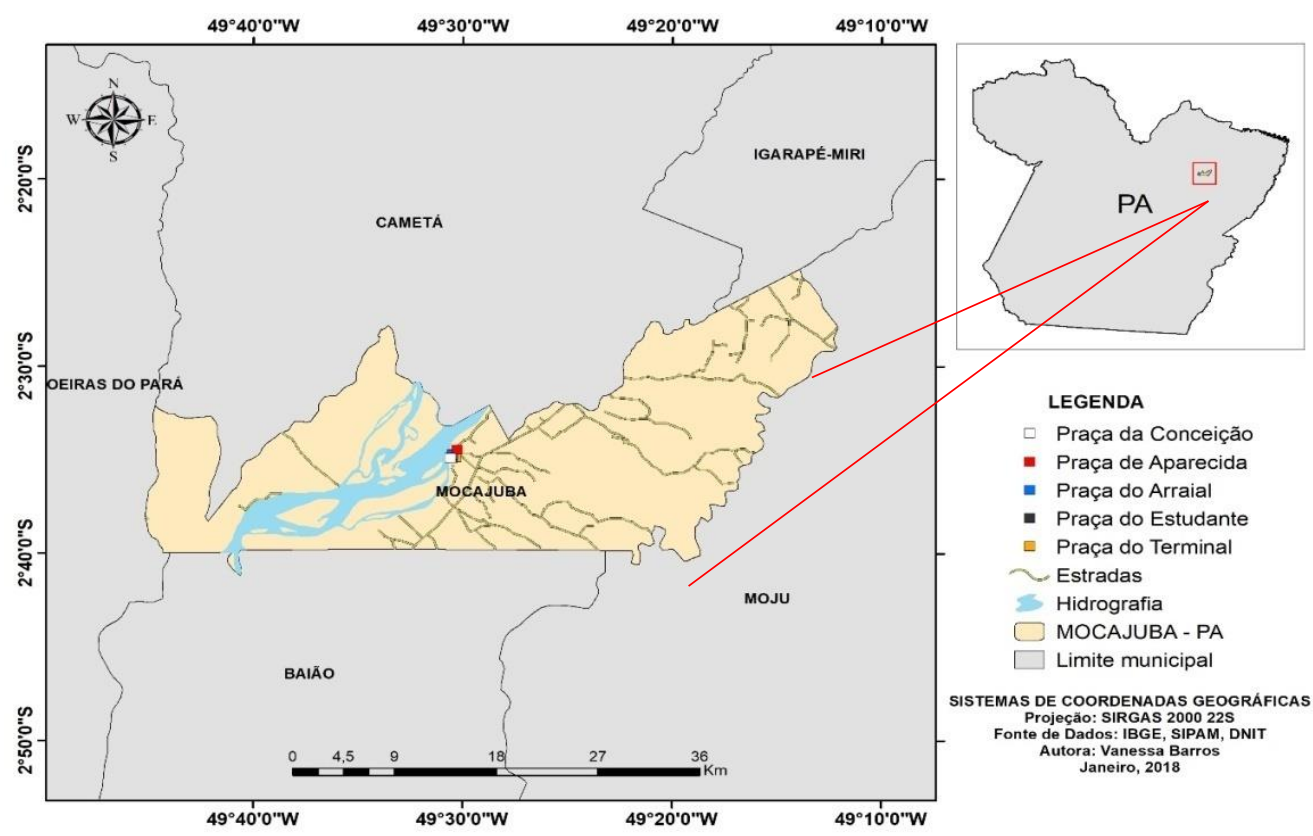

Figura 1. Localização do município de Mocajuba-PA

Figure 1. Location of the municipality of Mocajuba-PA

Em dimensões geográficas, Mocajuba é o menor município da microrregião Tocantina, no entanto, está entre aqueles que mais progrediram nas últimas décadas com a urbanização. A principal riqueza é oriunda de atividades como o cultivo da pimenta-do-reino (Piper nigrum), cacau (Theobroma cacao) e do açaí (Euterpe oleracea).

De acordo com a Prefeitura Municipal de Mocajuba existem oito praças no município. Destas, para efeito do estudo, foram eleitas cinco (62,5\%) - já que as demais praças (37,5\%) estão em rotatórias do município, sem arborização e pouca frequência de usuários. . As praças selecionadas foram: Praça da Conceição, que é a praça central da Igreja Matriz; Praça do Estudante; Praça do Rosário no bairro do Arraial; Praça do terminal e; Praça de Nossa Senhora de Aparecida, no bairro Novo.

\section{Procedimentos metodológicos}

Para identificação botânica e descrição das espécies encontradas nas praças de Mocajuba - PA (Figura 2), foi feita uma análise visual das espécies ocorrentes (folhas, frutos, coloração), por meio do censo do componente arbóreo, a partir da metodologia adotada por Niemeyer (2018). O levantamento ocorreu no período de 28 de dezembro de 2017 a 8 de janeiro de 2018. Na identificação apenas a mangueira é uma angiosperma, mas no período de coleta encontrava-se sem sementes.

Nas cinco praças estudadas, anotou-se o nome vulgar, o nome científico, a circunferência à altura do peito (CAP) e, a altura estimada da circunferência por superposição de 
ângulos. Para mensuração das árvores, operou-se com auxílio de uma fita métrica de 50 metros em todos os indivíduos acima de 1 metro.

Foram utilizados os softwares Google Earth PRO® e ArcGis 10.1 para a representação gráfica do ambiente e, também, para localização espacial das cinco praças estudadas no município (Figura 2).

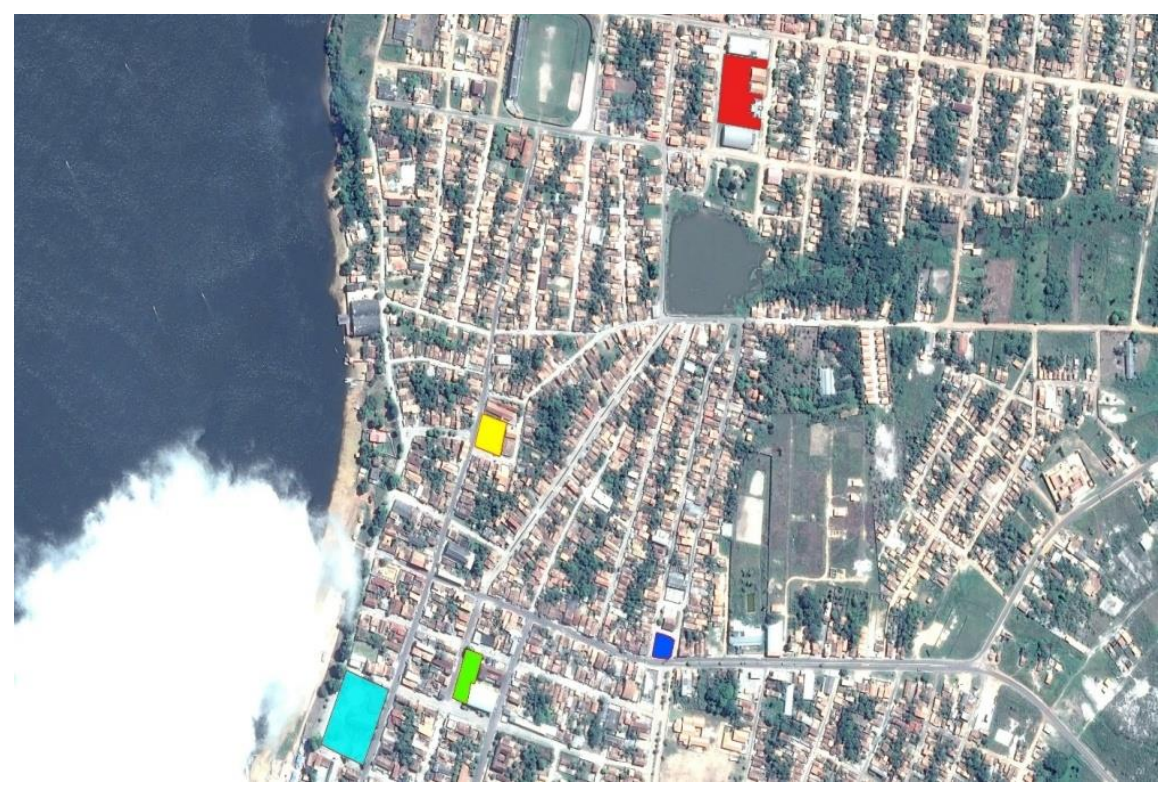

Fonte: Adaptado do Google (2018).

Figura 2. Área Urbana e localização das praças do município de Mocajuba (PA)

Figure 2. Urban Area and location of the squares of the municipality of Mocajuba (PA)

No mês de janeiro de 2018, foram realizadas cinco visitas em cada uma das cinco praças estudadas em diferentes momentos do dia (manhã, tarde e noite), a fim de abranger diferentes frequentadores desses espaços, após constatação de que crianças e idosos costumam frequentar esses locais nos horários da manhã e os mais jovens durante o período noturno. Para este trabalho foi adotada a terminologia citada por Costa e Colesanti (2011) que consideram a praça como área verde, tendo como principal função o lazer e encontro da população. Para os mesmos autores, a praça deixa de ser considerada uma área verde, quando não possui qualquer tipo de vegetação e se encontram impermeabilizadas.

No estudo da percepção ambiental, a amostragem foi não probabilística e aleatória com o preenchimento de 100 questionários destinados aos frequentadores desses espaços, a fim de se obter informações de uso e conservação desses ambientes públicos. Os estudos sobre percepção ambiental são importantes, pois permitem identificar o nível de conhecimento das populações sobre o tema abordado e contribuem para orientar estratégias e políticas públicas ambientais. Apesar da amostra não ter sido probabilística o quantitativo de 100 entrevistados, 
configura uma amostra representativa ao nível de 95\% de confiança e com margem de erro de $10 \%$, visto que a população de Mocajuba que é 30.377 habitantes.

As questões abordadas no questionário que dizem respeito ao perfil do entrevistado foram: sexo, idade, origem, nível de instrução e renda. A percepção ambiental foi avaliada através das seguintes questões: se a residência possui área verde, como ele classifica a arborização da praça, percepção sobre indivíduos arbóreos - cor, flor, porte, folhas, frutos, conjunto, se as árvores são agradáveis, o conhecimento que o entrevistado possui sobre a importância da arborização das praças, sensação ao caminhar na praça, conhecimento sobre outras praças do município, necessidade de mudanças nas praças do município). Os dados dos questionários foram tabulados em planilha do excel e apresentados por meio de estatística descritiva.

\section{RESULTADOS E DISCUSSÃO}

\section{Levantamento arbóreo}

De acordo com o levantamento realizado, foram encontradas 37 árvores de 10 famílias botânicas e 10 espécies arbóreas distribuídas nas praças de Mocajuba (PA) (Quadro1).

Quadro 1. Famílias botânicas encontradas na área de estudo.

Quadre 1. Botanical families found in the study area.

\begin{tabular}{|l|l|l|l|}
\hline NOME VULGAR & NOME CIENTíFICO & FAMíLIA & ORIGEM \\
\hline Acácia-australiana & Acacia dealbata L. & Fabaceae & Exótica \\
\hline Acácia-de-sião & Senna siamea (LAM.) H.S. Irwin e R.C. Barneny & Fabaceae & Exótica \\
\hline Castanhola & Terminalia catappa L. & Combretaceae & Exótica \\
\hline Figueira & Ficus benjamina L. & Moraceae & Exótica \\
\hline Ipê-rosa & Handroanthus heptaphyllus (Vell.) Mattos & Bignoniaceae & Exótica \\
\hline Mangueira & Mangifera indica L. & Anacardiaceae & Exótica \\
\hline Nim & Azadirachta indica A. Juss & Meliaceae & Exótica \\
\hline Oiti & Licania tomentosa (Benth.) Fritsch & hrysobalanaceae & Nativa \\
\hline Palheteira & Clitoria fairchildiana R.A.Howard & Fabaceae & Nativa \\
\hline Pau-pretinho & Cenostigma tocantinum D. & Fabaceae & Nativa \\
\hline
\end{tabular}

Das espécies observadas três são nativas e sete são consideradas exóticas, no qual a mangueira (Mangifera indica Linn) teve maior representatividade com treze exemplares. Em seguida aparece a castanhola ( Terminalia catappa Linn) com um total de oito indivíduos, seguido 
da acácia de sião (Senna siamea Lam.) com cinco indivíduos. A figueira (Ficus benjamina Leaves), acácia australiana (Acacia dealbata Link), oiti (Licania tomentosa Benth.) e, ipê rosa (Handroanthus heptaphyllus Vell.) tiveram dois indivíduos arbóreos, respectivamente. O nin (Azadirachta indica A. Juss), o pau pretinho (Cenostigma tocantinum Ducke) e a palheteira (Clitoria fairchildiana R.A.Howard) ficaram com apenas um exemplar cada (Figura 3).

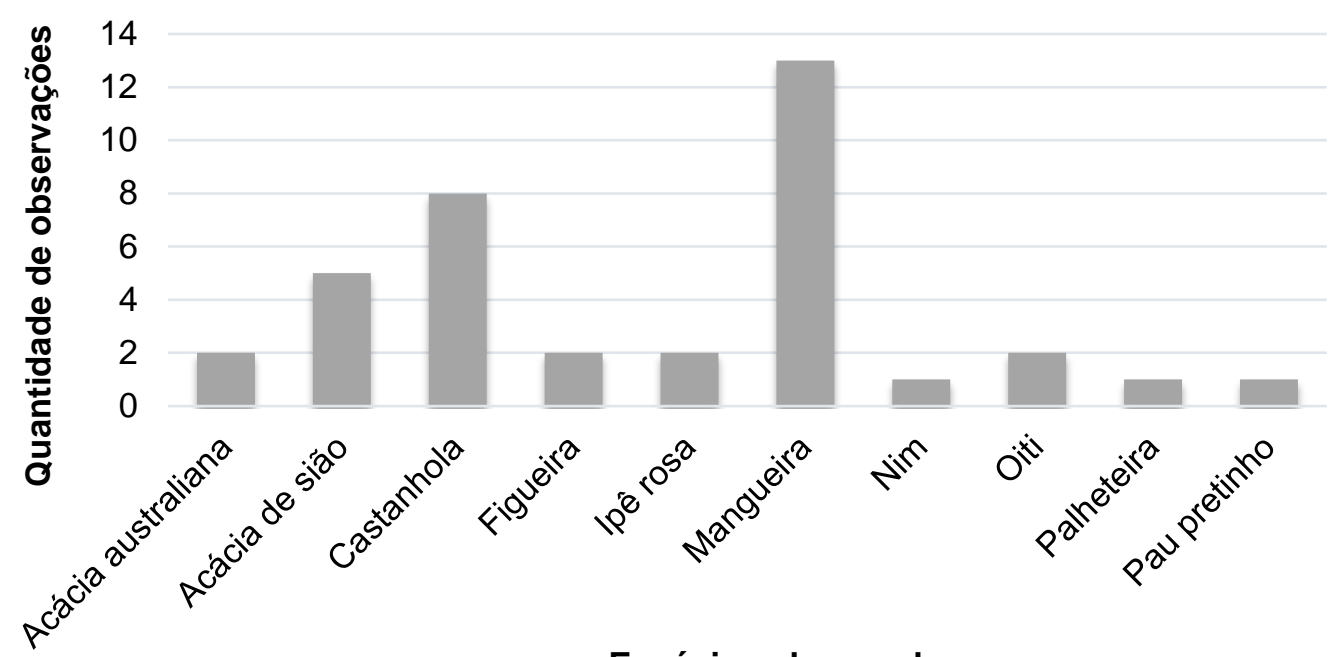

Espécies observadas

Fonte: Dados da pesquisa (2018).

Figura 3. Indivíduos arbóreos nas praças de Mocajuba (PA)

Figure 3. arboreal individuals in the squares of Mocajuba (PA)

A maior ocorrência da espécie (Mangifera indica Linn) decorre do costume regional enraizado, sob influência da capital Belém, que no final do século $X X$ teve as mangueiras consideradas patrimônio histórico cultural (IPHAN, 1994). Antônio Lemos (1843-1913), como intendente de Belém no período de 1897 a 1911, foi o responsável por iniciar a introdução das mangueiras na capital do estado do Pará, o qual induziu seu uso na arborização urbana nos demais municípios do estado (IPHAN, 1994).

Atualmente, a situação ambiental na capital paraense apresenta um triste cenário para as árvores, principalmente, quando se trata das mangueiras. Muitas delas apresentam copas deformadas em virtude de podas extremas, ocorrência de parasitas, frequentes quedas, devido ao envelhecimento e falta de cuidados básicos, além da competição por espaços, tanto com a fiação elétrica quanto com as calçadas, o que conforme Duarte, Sanches e Libardi (2012) deveria proporcionar mobilidade e ampla acessibilidade ao pedestre. A falta de manutenção nas árvores tende a fazer Belém perder o título de "capital das mangueiras".

Ademais, como destacam Duarte et al. (2018), a falta de corpo técnico e estrutura em muitas prefeituras dificultam as ações de implementação e manutenção da arborização urbana dificultando a qualidade ambiental nesses espaços. Fato similar ao constatado no município de 
Mocajuba quanto ao planejamento da arborização, especialmente com espécies regionais bem como a manutenção das praças.

\section{Identificação botânica e descrição das espécies encontradas}

Foi possível evidenciar que a maior parte das espécies encontradas nas cinco praças do município de Mocajuba - PA (Figura 4), obedece a disposição crescente, de outros municípios da Amazônia que é a implantação de diversos indivíduos arbóreos que não possuem origem regional. Loureiro e Barbosa (2010) avaliam que estas escolhas estão baseadas no imediatismo e o improviso do paisagismo, na tentativa de criar ambientes existentes no Sul do Brasil e na Europa.
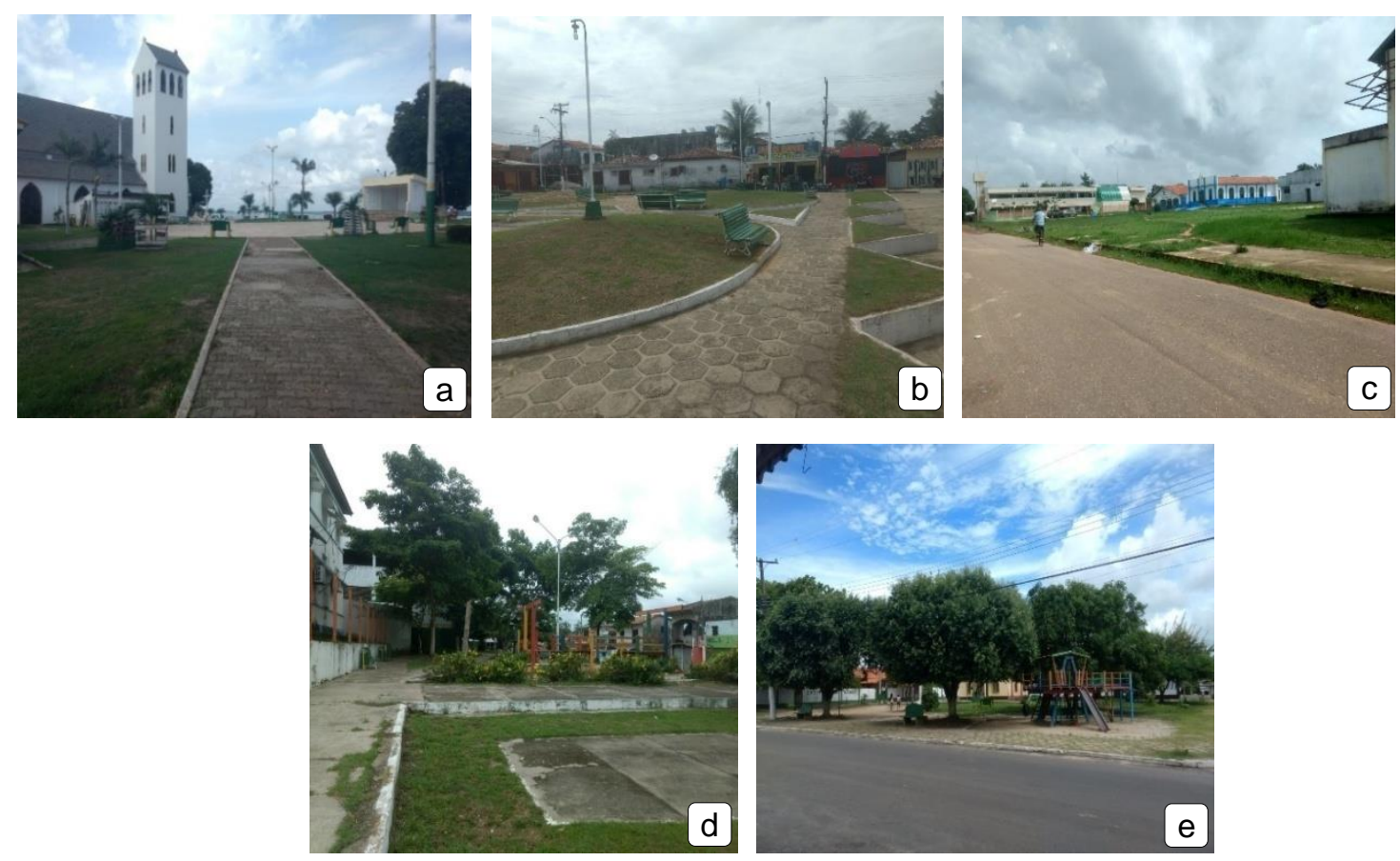

Figura 4. Vista panorâmica das praças do município de Mocajuba (PA), 2018. A) Praça da Conceição; B) Praça do Terminal; C) Praça da Aparecida; D) Praça do Estudante; E) Praça do Arraial

Figure 4. Panoramic view of the squares of the municipality of Mocajuba (PA), 2018. A) Conceição Square; B) Terminal Square; C) Aparecida Square; D) Student's Square; E) Arraial Square

Nota-se que a caracterização dos espaços verdes em Mocajuba, ainda necessita de estudos mais aprofundados e orientação técnica, principalmente, no que diz respeito aos conhecimentos das espécies amazônicas. Vale frisar que este é um importante espaço a ser ocupado por profissionais da área florestal, considerando que o mercado cada dia mais tende a valorizar no planejamento arbóreo, o uso de espécies nativas. Como destacam Silva e Perelló (2010), o emprego de espécies nativas em espaços urbanos possibilita a reaproximação da 
sociedade com a riqueza regional, alcançando os objetivos da educação ambiental, conforme Lei 9.795 de 1999, que contribui para difusão da identidade paisagística natural e regional.

\section{A percepção dos usuários nas praças}

Dentre os entrevistados por sexo $50 \%$ são de homens e $50 \%$ de mulheres. Cerca de $60 \%$ dos moradores são naturais do próprio município, os outros $40 \%$ são de municípios que fazem fronteira com Mocajuba, entre eles Cametá (13,3\%), Baião (10,0\%) e da capital paraense $(16,7 \%)$.

Houve grande variação na idade dos entrevistados, cuja amplitude está entre 15 a 81 anos. Brígido e Hirao (2011) alcançaram resultados diferentes, pois, 75\% dos frequentadores em sua pesquisa estavam representados no intervalo etário entre 20 a 50 anos e os demais acima dos 60 anos. Pode-se explicar tal variação em decorrência de que o estudo foi realizado nos turnos da manhã, tarde e noite, o que facilitou a obtenção de grande amplitude etária entre os respondentes em Mocajuba - PA.

A análise dos dados obtidos quanto ao grau de escolaridade dos indivíduos amostrados, indicou que $23,3 \%$ concluíram o ensino superior completo e o ensino básico completo. Uma pequena parcela, $10 \%$ possui ensino médio incompleto e ensino básico incompleto (Figura 5). Tais valores se assemelham aos encontrados por Brígido e Hirao (2011) em um estudo na praça no município de Pinheiros - SP, que revelou que um percentual de 57\% dos entrevistados possuía o grau de escolaridade entre o ensino médio e superior completo, e apenas $10 \%$ dos frequentadores com ensino fundamental. Assim, é possível afirmar que as praças cada vez mais se tornaram um espaço de utilização comum, indistintamente em relação ao sexo, à idade e ao nível de instrução, o que pode ser explicado pelos benefícios de melhor qualidade de vida que a praça pode proporcionar aos moradores locais.

Quanto ao nível de renda o público também é bastante distinto, sendo que grande parte dos frequentadores (50\%) possui entre 2 a 5 salários mínimos. Na sequência tem-se $26,7 \%$ com um salário, 13,3\% são frequentadores sem rendimento e, $10 \%$ do público ganha mais de 5 salários mínimos (Figura 5). 


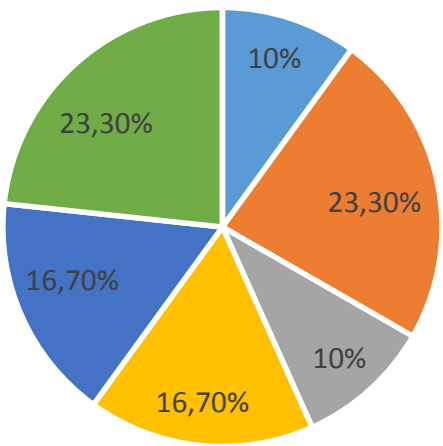

- ensino básico incompleto

- ensino básico completo

- ensino médio incompleto

- ensino médio completo

- ensino superior incompleto

- ensino superior completo

- NS/NR

Figura 5. Grau de escolaridade (a) e renda per capita dos usuários (b)

Figure 5. Degree of education (a) and per capita income of users (b)

Foi constatado que todos os entrevistados procuram o espaço como alternativa para proporcionar bem-estar físico e mental (a tranquilidade, o relaxamento, o sombreamento, o conforto térmico, a qualidade do ar). Desse modo, destaca-se que $83,3 \%$ do total dos entrevistados citaram saber qual a importância da arborização nas praças, destacando aspectos como sombreamento, oriundo do desenvolvimento das copas das árvores como a principal importância, seguido do conforto térmico e ar puro, garantidos pela manutenção das árvores nestes locais.

Vale frisar que $76,7 \%$ dos entrevistados revelaram ter conhecimento sobre todas as praças deste estudo, sendo que $73,3 \%$ dos entrevistados, consideram que todas as praças objetos desse estudo necessitam de mudanças estruturais (melhor arborização e planejamento técnico) além de manutenção prévia de seus componentes.

Ainda existem muitos desafios a serem superados para que a arborização seja considerada satisfatória, proporcionando maior qualidade ambiental à população urbana. A valorização e o planejamento da arborização urbana com espécies regionais endêmicas, uma melhor infraestrutura das praças e os investimentos em capacitação de técnicos das prefeituras são aspectos que devem ser considerados nas ações dos órgãos competentes visando uma melhor qualidade de vida das populações locais, pois conforme a pesquisa $83,3 \%$ sabem a importância da arborização nas praças.

Quanto a percepção dos respondentes sobre as árvores presentes nesses ambientes públicos (Figura 6), 30\% dos entrevistados respondeu que o conjunto (cor, flor, porte, folhas, frutos, conjunto) chama mais atenção, sendo o porte do indivíduo arbóreo uma característica destacada por $20 \%$ dos entrevistados, seguido de frutos com aproximadamente $17 \%$ e, de cores 
com $13 \%$ do total de entrevistados. Tais impressões revelam que ainda se faz necessário o estudo aprofundado sobre os vegetais inseridos ao acaso nos logradouros públicos, oportunizando a comunidade ao redor destes ambientes, conhecimento sobre os benefícios que determinadas espécies podem proporcionar.

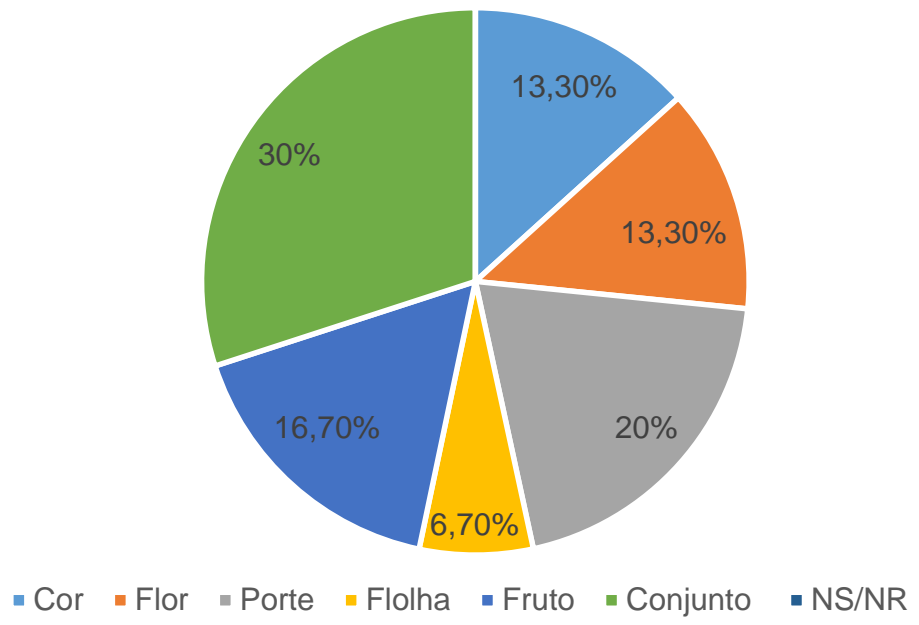

Figura 6. Parte da árvore que mais chama atenção

Figure 6. Part of the tree that catches the most attention

\section{CONCLUSÕES}

As espécies exóticas foram as mais frequentes na arborização das cinco praças do município de Mocajuba (PA), sendo a mais encontrada a mangueira (Mangifera indica L.).

A análise da percepção ambiental comprovou que $83,3 \%$ dos usuários consultados têm o conhecimento sobre a importância da arborização das praças, além de considerarem em 73\% dos casos que todas as praças estudadas necessitam de melhor arborização, de ações públicas, de técnicas de planejamento e manutenção desses espaços. Isso denota que a população local compreende os benefícios da arborização urbana para uma melhor qualidade de vida da população, a despeito da deficiência no município de Mocajuba. 


\section{REFERÊNCIAS}

BARGOS, D. C.; MATIAS, L. F. Áreas verdes urbanas: um estudo de revisão e proposta conceitual. REVSBAU, Piracicaba, v. 6, n. 3, p. 172-188, 2011.

BRÍGIDO, N. M.; HIRAO, H. A praça Victor Civita e o desenvolvimento sustentável: uma avaliação do uso, apropriação e imaginário. Revista Tópos, São Paulo, v. 5, n. 2, p. 09-20, 2011.

COSTA, R. G. S.; COLESANTI, M. M. A contribuição da percepção ambiental nos estudos das áreas verdes. RAEGA, Curitiba, n. 22, p. 238-251, 2011.

DUARTE, F.; SANCHES, K.; LIBARDI, R. Introdução à mobilidade urbana, Curitiba: Juruá, 2012.

DUARTE, T. E. P. N.; ANGEOLETTO, F.; SANTOS, J. W. M. C.; SILVA, F. F. da; BOHRER, J. F. C.; MASSAD, L. Reflexões sobre arborização urbana: desafios a serem superados para o incremento da arborização urbana no Brasil. Rev. Agro. Amb., Maringá, v. 11, n. 1, p. 327-341, 2018.

INSTITUTO BRASILEIRO DE GEOGRAFIA E ESTATÍSTICA. Censo Demográfico 2010: Características urbanísticas do entorno dos domicílios, 2010. Disponível em: https://ww2.ibge.gov.br/home/estatistica/populacao/censo2010/entorno/default_entorno.shtm.A cesso em: 15 jan. 2018.

INSTITUTO BRASILEIRO DE GEOGRAFIA E ESTATÍSTICA. Coordenação de População e Indicadores Sociais - COPIS. Mocajuba, Pará, $2017 . \quad$ Disponível em:<https://cidades.ibge.gov.br/brasil/pa/mocajuba/panorama>. Acesso em: 15 jan. 2018.

INSTITUTO DO PATRIMÔNIO HISTÓRICO E ARTÍSTICO NACIONAL. Lei de Patrimônio Histórico, $\mathrm{n}^{\circ}$ 7.709, de 18 de maio de 1994. Disponível em:< http://portal.iphan.gov.br/portal/baixaFcdAnexo.do?id=205>. Acesso em: 20 jan. 2018.

LIMA NETO, E. M.; SOUZA, R. M. Comportamento e características das espécies arbóreas nas áreas verdes públicas de Aracaju, Sergipe. Scientia Plena, Sergipe, v. 7, n. 1, p. 01-10, 2011.

LOUREIRO, V. R.; BARBOSA, E. J. da. Cidade de Belém e natureza: uma relação problemática? Novos Cadernos NAEA, Belém, v. 13, n. 1, p. 105-134, 2010.

NIEMEYER, C. A. C. Percepção ambiental como estratégia de investigação em arquitetura: um estudo de caso. Revista Projetar, Natal, v.3, n.1, p. 44-52, 2018.

PORTO, L. P. M.; BRASIL, H. M. S. Manual de Orientação Técnica da Arborização Urbana de Belém: guia para planejamento, implantação e manutenção da arborização em logradouros públicos, Belém: Universidade Federal Rural da Amazônia, 2013. Disponível em <http://ww3.belem.pa.gov.br/www/wp-content/uploads/Manual-de-Arboriza\%C3\%A7\%C3\%A3ode-Bel\%C3\%A9m.pdf>. Acesso em: 09 set.2017.

SILVA, J. G.; PERELLÓ, L. F. C. Conservação de espécies ameaçadas do Rio Grande do Sul através de seu uso no paisagismo. REVSBAU, Piracicaba, v. 5, n. 4, p. 01-21, 2010.

SILVA, L. M.; HASSE, I.; MOCCELIN, R.; ZBORALSKI, A. R. Arborização de vias públicas e a utilização de espécies exóticas: O caso do bairro centro de pato branco/PR. Scientia Agraria, Curitiba, v. 8, n. 1, p. 47-53, 2007. 